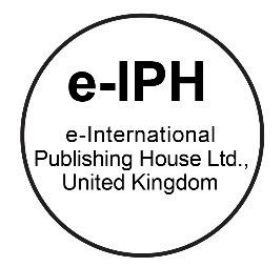

\title{
Profiling MOOC Learners in a Higher Learning Institute in Malaysia
}

\author{
Chan Yuen Fook, Suthagar Narasuman, Asmahan Abd Razak, Nurul Fitriah Alias. \\ Faculty of Education, \\ Universiti Teknologi MARA, Selangor Branch, Puncak Alam Campus, 42300 Puncak Alam Selangor Malaysia \\ yuenfook@uitm.edu.my; suthagar@uitm.edu.my: asmahan@uitm.edu.my; nurulfitriah@uitm.edu.my \\ Tel: $603-32584941$
}

\begin{abstract}
The focus of this study is to explore the profile of students who subscribed to MOOCs as a flexible learning option. The study was based on an analysis of the respondent's profile and demographic data. The findings show that students had signed up for MOOCs in their last semester because they considered it to be a flexible learning option. The study found that there were no significant differences among the users' demographic data, particularly gender and age. The only difference was in the chosen program of course via the MOOC platform.
\end{abstract}

Keywords: Massive Open Online Course, MOOC user usage, gender, age, the program of study

eISSN: 2398-4287@ 2020. The Authors. Published for AMER ABRA CE-Bs by e-International Publishing House, Ltd., UK. This is an open access article under the CC BYNC-ND license (http://creativecommons.org/licenses/by-nc-nd/4.0). Peer-review under responsibility of AMER (Association of Malaysian Environment-Behaviour Researchers), ABRA (Association of Behavioural Researchers on Asians) and cE-Bs (Centre for Environment-Behaviour Studies), Faculty of Architecture, Planning \& Surveying, Universiti Teknologi MARA, Malaysia.

DOI: https://doi.org/10.21834/ebpj.v5iSI3.2556

\subsection{Introduction}

Online learning via Massive Open Online Courses (MOOC) has attracted a diverse range of participants to enrol in various programs offered globally. Learning via the MOOC platform enables participation from various age groups, nationality and program of study to enrol in courses of their interest. Millions of people, ranging from students to working adults and even professionals who want to enhance their knowledge or expertise, have enrolled in Massive Open Online Courses (MOOCs). Professionals, educators, researchers, students and the general public have displayed a keen interest in learning via MOOCs to experience online learning first hand. Breslow, Pritchard, DeBoer, Stump, Ho, \& Seaton (2013) mentioned that enrollment in MOOCs stretches over 196 countries. Subscribers speak a wide variety of languages and consist of a wide range of age and education. They are also highly heterogeneous and motivated to participate in online courses. Over the past couple of years, a host of MOOC platforms had been developed. Among the popularly subscribed ones are, Coursera, edX, Udacity, Udemy and Open Learning. However, not all MOOC courses are suitable or cater to individuals and the diverse cultural variabilities in learning styles. To succeed in online learning, learners have to be "selfdirected autodidact" (Kizilcec, 2013).

\subsection{Method}

This is a descriptive study and data was obtained using a survey questionnaire. The respondents are students who use MOOC as an online learning platform at a local public university in Malaysia. $73 \%$ of the respondents returned completed questionnaires. $\mathrm{A}$

eISSN: 2398-4287C 2020. The Authors. Published for AMER ABRA cE-Bs by e-International Publishing House, Ltd., UK. This is an open access article under the CC BYNC-ND license (http://creativecommons.org/licenses/by-nc-nd/4.0/). Peer-review under responsibility of AMER (Association of Malaysian Environment-Behaviour Researchers), ABRA (Association of Behavioural Researchers on Asians) and cE-Bs (Centre for Environment-Behaviour Studies), Faculty of Architecture, Planning \& Surveying, Universiti Teknologi MARA, Malaysia. DOI: https://doi.org/10.21834/ebpj.v5iSI3.2556 
response rate of above $70 \%$ is adequate to glean information from the target population and provide meaningful statistical analyses (Draugalis, Coons \& Plaza, 2008). The questionnaire for this study was adapted from an e-learning study by Onah, Sinclair and Boyatt's (2014) conducted at the University of Southampton. The Cronbach alpha reliability index of the questionnaire used was .735, and therefore it was deemed as a reliable instrument for this study. For the study, MOOC Learners' Usage was set as the dependent variable, while age, gender and program of study were selected as independent variables. Firstly, a descriptive analysis was conducted to analyze the profile of MOOC learners in terms of usage habits and devices. Secondly, a t-test and one-way ANOVA analyses were conducted to analyze $\mathrm{MOOC}$ usage among the respondents based on gender, age and program of study.

\subsection{Results}

\subsection{Profile of MOOC Learners}

The majority of the respondents were females who made up $79.5 \%(n=58)$ and males $20.5 \%(n=15)$ respectively. Regarding age, respondents aged 20-24 years formed the biggest group, 69.9\% $(n=51)$ followed by respondents aged between $25-29$ years who formed $23.3 \%(n=17)$ of the total number, while respondents aged between $35-39$ years formed $5.5 \%(n=4)$ of the total number. The smallest age group was $30-34$ years, which formed $1.4 \%(n=1)$ of the total number of respondents. This result shows that the respondents under 30 years old were the dominant group in this study. The result based on ethnicity shows that Malay respondents were the largest group in this study $(89 \%, n=65)$, followed by respondents from indigenous groups in Sabah $(5.5 \%$, $n=4)$. However, missing data is recorded at $5.5 \%(n=4)$ due to respondents who did not state their ethnicity. Based on the program of study, undergraduates formed the majority $(58.9 \%, n=43)$ followed by respondents enrolled in master's degree programmes $(41.1 \%, n=30)$. Respondents who study full time formed the majority $(98.6 \%, n=72)$ and part-time students were the least $(1.4 \%, n=1)$. Forty-nine respondents regarded themselves as active learners (67.1\%), while 24 respondents regarded themselves as passive learners $(32.9 \%)$.

\subsection{MOOC's Usage Habits among the Learners}

Table 1 shows that the overall mean for MOOC usage among the respondents was at a moderate level (mean=2.12, $S D=.520, n=73)$. Further analysis of online participation other than MOOC among the respondents revealed that only 39 of them had engaged in online courses, which is slightly higher than the rest. This shows that participation in online learning platforms is something new for the respondents in this study. Data analysis shows that $47.9 \%$ of the respondents had only recently joined a MOOC. The results also show that $32.9 \%$ had enrolled in a MOOC within the last six months before the study, and only $6.8 \%$ had enrolled within one year before the survey, respectively. The respondents engaged in online learning at various times of the day. Most of the respondents in this study prefer to use MOOCs at night, which made up $28.8 \%$, while $21.9 \%$ only use the platform during weekends while $17.8 \%$ use it during daytime and a further $12.3 \%$ use them only in the morning hours. The least amount of time to use a MOOC forum was during vacations (1.4\%). As university students, most respondents in this study accessed their MOOC platforms at home $(75.3 \%)$ and the campus dormitory $(19.2 \%)$. The rest of the respondents accessed their MOOCs at the campus library $(1.4 \%)$, internet cafés $(1.4 \%)$ and other places where Wi-Fi is available $(1.4 \%)$.

Table 1. MOOC Usage among the Learners $(n=73)$

\begin{tabular}{lcc}
\hline & Table 1. MOOC Usage among the Learners $(\mathrm{n}=73)$ & \\
\hline Variable & Mean & .51 \\
\hline Number of MOOCs - Current & 2.16 & .50 \\
Number of MOOCs - Completed & 2.10 & .53 \\
Frequency of MOOCs - Attending Per week & 2.15 & .52 \\
Frequency of MOOCs - Completed Per week & 2.08 & 0.52 \\
\hline MOOC Usage $\quad$ Scale: $<1.66$ = Low, & 2.12 & $3.34-5.00=$ High
\end{tabular}

As mentioned before, most respondents joined a MOOC quite recently. Thus most of them had experienced between $1-3$ courses $(90.4 \%)$, while $4.1 \%$ stated they had joined $4-6 \mathrm{MOOC}$ courses, $2.7 \%$ more than $10 \mathrm{MOOC}$ courses and the least, $1.4 \%$ said that they are currently on their $7^{\text {th }}-9^{\text {th }}$ MOOC course. With regards to networking and collaboration, $54.8 \%(n=40)$ of the respondents stated they had not communicated with other MOOC users, while $45.2 \%$ ( $n=33$ ) said that they interact with other MOOC users.

Table 2 provides the analysis with regards to the use of various electronic gadgets, devices and media by the respondents to access their MOOC accounts. The results showed that $71.2 \%$ of the respondents used laptops, while $23.3 \%$ preferred desktops. Tablets or iPads were the least used devices (1.4\%), while mobile devices accounted for $2.7 \%$ of the respondents.

Regarding the choice of media on their learning platform, $32.9 \%$ of the respondents preferred streaming videos, $26 \%$ preferred blogs and $13.7 \%$ chose open source tools/materials. However, $8.2 \%$ preferred MOOC forums and a further $8.2 \%$ preferred to use google. The least preferred mediums were Facebook (4.1\%), Twitter $(2.7 \%)$ and skype $(2.7 \%)$. A pertinent point to note is that the 
majority of the respondents in this study had used Open Learning (97.3\%) as their MOOC platform. A compelling reason for this is that the faculty members at this university were actively producing online resources using Open Learning as their platform.

The study had also conducted a t-test, as shown in Table 3, which found that gender [t(72)=-.827, p-value >.05] did not show any significant difference among respondents usage of MOOCs as an online learning platform. However, the program of study [t $(72)=2.108, p$-value <.05] did show a significant difference. Hence, the usage of MOOCs was not influenced by gender. Still, the program of study did make a substantial difference among higher education learners where undergraduate degree students chalked a higher rate of usage in comparison to students enrolled in master's programmes.

Table 2. Descriptive Analyses of MOOC Learners' Device Usage $(n=73)$

\begin{tabular}{|c|c|c|c|c|}
\hline No. & Items & Options & No. of Respondents & Percentage (\%) \\
\hline 1 & Electronic device to access $\mathrm{MOOC}$ & $\begin{array}{l}\text { Laptop } \\
\text { Desktop } \\
\text { Mobile device } \\
\text { Tablet/iPad } \\
\text { Others }\end{array}$ & $\begin{array}{l}52 \\
17 \\
2 \\
1 \\
1\end{array}$ & $\begin{array}{l}71.2 \\
23.3 \\
2.7 \\
1.4 \\
1.4\end{array}$ \\
\hline 2 & Use of media to learn MOOC & $\begin{array}{l}\text { Online videos } \\
\text { Blog } \\
\text { Open source tools/materials } \\
\text { In-MOOC forum } \\
\text { Google } \\
\text { Facebook } \\
\text { Twitter } \\
\text { Skype } \\
\text { Missing }\end{array}$ & $\begin{array}{l}24 \\
19 \\
10 \\
6 \\
6 \\
3 \\
2 \\
2 \\
1\end{array}$ & $\begin{array}{l}32.9 \\
26.0 \\
13.7 \\
\\
8.2 \\
8.2 \\
4.1 \\
2.7 \\
2.7 \\
1.4\end{array}$ \\
\hline 3 & MOOC platform & $\begin{array}{l}\text { Open Learning } \\
\text { Courser } \\
\text { Missing }\end{array}$ & $\begin{array}{l}71 \\
1 \\
1 \\
\end{array}$ & $\begin{array}{l}97.3 \\
1.4 \\
1.4 \\
\end{array}$ \\
\hline
\end{tabular}

Table 3. Independent Samples t-test of MOOC Learners' Usage-based on Gender and Program of Study

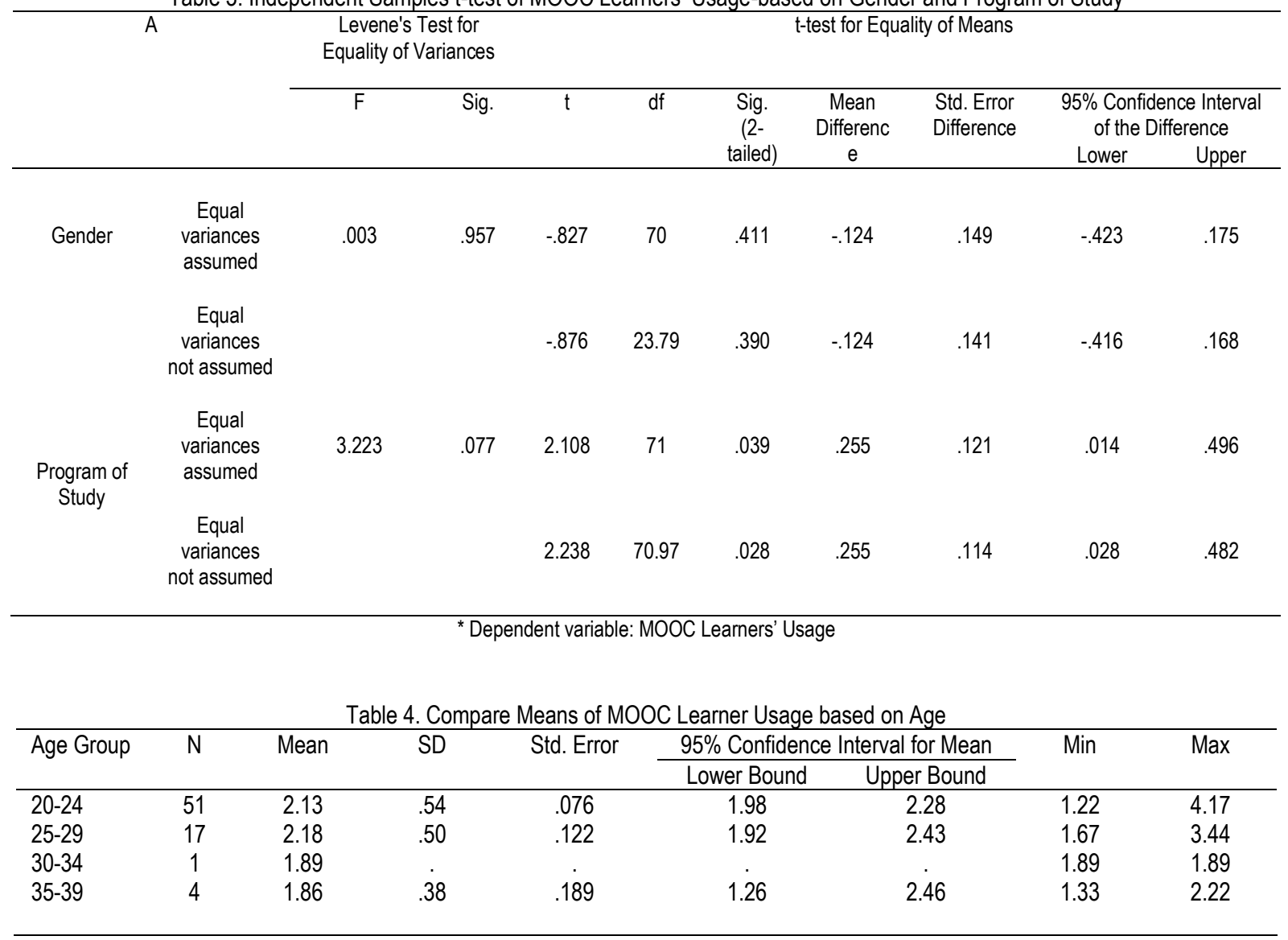




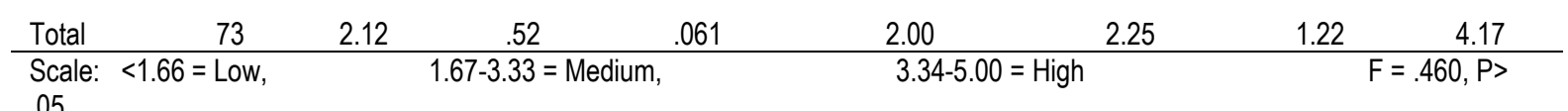

MOOC Learners' Usage-based on age revealed that moderate means had been identified among the four different age groups of respondents. Homogeneity of Variance test $(F=.401, p>.05)$ has confirmed that equality of variance had been ensured. The ANOVA result shows the different number of respondents in the age groups did not affect. One-way ANOVA analysis in Table 4 further confirmed that there were no significant differences had been identified among the different age groups of MOOC learners in terms of MOOC usage with $F=.460, p>05$.

\subsection{Discussion and Recommendations}

The findings of this study had revealed that the majority of the respondents were females, aged around 20-24 years old and hold a bachelor's degree. These demographic patterns are similar to a study done by Hansen \& Reich (2015). The study has also highlighted that gender and age did not cause any significant difference in the usage of MOOCs among learners in higher education institutions. The only significant difference was between undergraduate and postgraduate students. These findings suggest that preference for using MOOCs among tertiary students cannot be predicted based on gender and age, but program levels do have an impact on their selection. These findings are parallel to the findings reported in the studies of Guo \& Reinecke (2014) and Christensen et al. (2013).

However, the findings of the present study contradict studies done by DiBiase \& Kidwai (2010), who found that age and gender except education level have influenced learner's engagement with MOOCs. This study is also in contrast with a study sponsored by HarvardX and MITx and undertaken by Ho, Reich, Nesterko, Seaton, Mullaney, Waldo \& Chuang (2014) which revealed mixed results in terms of gender and age except for the level of participants' education. According to Ho et al. (2014), most HarvardX and MITx's participants were aged below than 30 years in every course in which the middle-aged was 26 years old. Nonetheless, the study shows similar patterns concerning the education level of the respondents as reported in HarvardX and MITX, whereby most respondents hold a bachelor's degree. In contrast, a significant number of respondents have a higher level of education. However, in terms of gender, the HarvardX and MITx study reported that male respondents participated more actively than females in MOOC platforms.

The results of this study may differ from some previous studies, mainly since MOOCs are a new concept of online learning in Malaysian higher education institutions. Hence there might be limited and insufficient information as well as limited coverage of MOOC usage as a learning platform among students. This could be the underlying reason for low levels of participation and engagement in online learning platforms such as MOOCs. Also, most students in higher public education institutions in this country are predominantly females (Department of Statistic, 2017). As a new online learning concept, the student respondents do not seem to be familiar with the idea yet.

Furthermore, the education system in Malaysia is still mainly practising traditional classroom teaching and learning methods and approaches. The MOOC approach is still not grounded in a Malaysian learning culture, and students have not shifted their mindset to get used to the online learning concept. Hence, educators and education departments must take progressive efforts to ensure online courses such as MOOC can be accepted widely. Not only by tertiary students but also by professional workers and the public, in general, to stay relevant with this advanced tool in the digital era.

The study found insignificant results about MOOC usage among students of higher education in terms of age and gender except for the education level of the students. Nevertheless, respondents acknowledged the significance of MOOCs in widening their knowledge (Hansen \& Reich, 2015). The respondents believed that MOOC, as a learning platform, has met their expectations and would engage more with $\mathrm{MOOC}$ courses in the future. They hope that their educators/instructors could integrate more online platforms as a teaching approach in their programs and course of study. This allows them to learn and retrieve learning materials anytime and anywhere. Learning via MOOCs will be entirely accepted if Malaysian educators integrate online learning in their teaching method.

\subsection{Conclusion}

Although MOOC as a learning concept is not something new in developed nations, in countries like Malaysia, students have not fully embraced this new frontier due to lack of exposure. In this context, it is pertinent that educators and the Ministry of Education (MoE) should cooperate in updating and enlisting various forms of mediated online learning platforms and digital media that the advent of industry 4.0 has to offer students. Effective and appropriate measures are needed to encourage more use of MOOCs at the university level as a learning concept. MOOCs provide a convenient and flexible approach to learning today. Malaysian students will be left behind if the relevant authorities do not take the necessary steps to provide students with the required facilities to engage with MOOCs in our higher education institutions.

\section{Acknowledgements}

This paper is part of a research project funded by the BESTARI Grant from the Institute of Research Management and Innovation (IRMI), Universiti Teknologi MARA (Project Code: 600-IRMI/DANA 5/3/BESTARI (00016/2016). 


\section{References}

Breslow, L., Pritchard, D.E., DeBoer, J., Stump, G.S., Ho, A.D. \& Seaton, D.T. (2013). Studying learning in the worldwide classroom: Research into edX's first MOOC.Research and Practice in Assessment, 8.

Christensen, G., Steinmetz, A., Alcorn, B., Bennett, A., Woods, D. \& Emanuel, E.J. (2013). The MOOC phenomenon: Who takes massive open online courses, and why? Retrieved from http://papers.ssrn.com/abstract=2350964

Department of Statistic, Malaysia. (2016). Bilangan enrolmen universiti awam mengikut jantina bagi tahun 2016. Retrieved from http://www.data.gov.my/data/ms_MY/dataset/38e55740-4184-432e-a844-347d67df3e36/resource/02106eea-d575-4fb9-9385 ecb2a8a19540/download/2016enrolmenuabyjantina.csv

DiBiase, D. \& Kidwai, K. (2010). Wasted on the young? Comparing the performance and attitudes of younger and older US adults in an online class on geographic information. Journal of Geography in Higher Education, 34(3), 299-326.

JoLaine Reierson Draugalis, Stephen Joel Coons, and Cecilia M. Plaza (2008). Best Practices for Survey Research Reports: A Synopsis for Authors and Reviewers.American Journal of Pharmaceutical Education: Volume 72, Issue 1, Article 11.

Guo, P.J. \& Reinecke, K. (2014). Demographic differences in how students navigate through MOOCs. ACM, 1-10.

Hansen, J.D. \& Reich, J. (2015). Democratizing education? Examining access and usage patterns in massive open online courses. Science, 350(6265), 1245-1248.

Ho, A.D., Reich, J., Nesterko, S., Seaton, D.T., Mullaney, T., Waldo, J. \& Chuang, I. (2014). HarvardX and MITx: The first year of open online courses, Fall $2012-$ Summer 2013 (HarvardX and MITx Working Paper No. 1).

Kizilcec, R.F. (2013). Collaborative Learning in Geographically Distributed and In-person Groups. In AIED 2013 Workshop on Massive Open Online Courses.

Onah, Daniel F. O., Sinclair, Jane and Boyatt, Russell (2014). Dropout rates of massive open online courses: Behavioural patterns. In: 6th International Conference on Education and New Learning Technologies, Barcelona, Spain, 7-9 Jul 2014. Published in: EDULEARN14 Proceedings pp. 5825-5834. ISBN 9788461705573. ISSN 2340-1117.: Prospects for internationalization. Retrieved Jan 5, 2017, from http://mahzan.com. 